\title{
Insights into ice stream dynamics through modelling their response to tidal forcing
}

\author{
S. H. R. Rosier ${ }^{1,2}$, G. H. Gudmundsson ${ }^{2}$, and J. A. M. Green ${ }^{1}$ \\ ${ }^{1}$ School of Ocean Sciences, Bangor University, Menai Bridge, LL59 5AB, UK \\ ${ }^{2}$ British Antarctic Survey, High Cross, Madingley Rd., Cambridge, CB3 0ET, UK \\ Correspondence to: S. H. R. Rosier (s.rosier@bangor.ac.uk)
}

Received: 6 December 2013 - Published in The Cryosphere Discuss.: 23 January 2014

Revised: 14 May 2014 - Accepted: 14 August 2014 - Published: 25 September 2014

\begin{abstract}
The tidal forcing of ice streams at their ocean boundary can serve as a natural experiment to gain an insight into their dynamics and constrain the basal sliding law. A nonlinear 3-D viscoelastic full Stokes model of coupled ice stream ice shelf flow is used to investigate the response of ice streams to ocean tides. In agreement with previous results based on flow-line modelling and with a fixed grounding line position, we find that a nonlinear basal sliding law can qualitatively reproduce long-period modulation of tidal forcing found in field observations. In addition, we show that the inclusion of lateral drag, or allowing the grounding line to migrate over the tidal cycle, does not affect these conclusions. Further analysis of modelled ice stream flow shows a varying stress-coupling length scale of boundary effects upstream of the grounding line. We derive a viscoelastic stresscoupling length scale from ice stream equations that depends on the forcing period and closely agrees with model output.
\end{abstract}

\section{Introduction}

The Antarctic ice sheet is surrounded by ocean, and changes in this boundary forcing have important implications for its flow and future evolution. Ocean tides play an important role in ice dynamics of the continent: inducing currents that alter basal melting beneath the floating ice shelves (Makinson et al., 2011), affecting the motion of the ice shelves (Doake et al., 2002; Brunt et al., 2010; Makinson et al., 2012) and causing changes in short-term and mean flow of ice streams, often far upstream of the grounding line (Anandakrishnan et al., 2003; Bindschadler et al., 2003a, b; Gudmundsson, 2006; Murray et al., 2007; Marsh et al., 2013).
Ice streams are regions of fast moving ice that form a link between the ice sheet and ice shelves, where most of the mass is lost from the continent, with implications for sea level rise (Vaughan, 2005; Alley et al., 2005; Church et al., 2013). In spite of the key role they play in ice mass loss from the Antarctic continent, there are still many questions regarding the mechanisms controlling their flow.

The widespread use of GPS to measure ice stream flow has made high temporal resolution data available, which was not previously possible with remote sensing techniques. The tidal signal in these measurements is easily distinguishable and can be used as a natural experiment to gain an insight into ice stream dynamics, in particular the nature of the basal sliding law (Gudmundsson, 2007, 2011; King et al., 2011; Walker et al., 2012; Goldberg et al., 2014). GPS observations of a strong tidal modulation of ice stream velocities at longer periods than the vertical ocean tidal forcing at the grounding line have raised questions about what mechanism could explain this, and some of these theories are discussed in more detail below.

While previous studies have identified some key processes involved and demonstrated how the response is affected by basal conditions, all studies to date have been limited to flowline situations, i.e. one horizontal dimension (1HD). It has thus not been possible to assess the effects in the transverse direction of the response of ice streams to tidal forcing. Given the importance of side drag in controlling the flow of ice streams, this raises questions about the applicability of 1HD modelling studies. Here, we use a three-dimensional nonlinear viscoelastic model to address these open issues. A separate, two-dimensional high-resolution model with migrating grounding line is also used. In agreement with a previous 
Table 1. Tidal constituents and their respective periods.

\begin{tabular}{lr}
\hline $\begin{array}{l}\text { Tidal } \\
\text { constituent }\end{array}$ & Period (days) \\
\hline $\mathrm{Msf}$ & 14.765 \\
$\mathrm{Mf}$ & 13.661 \\
$O_{1}$ & 1.075 \\
$K_{1}$ & 0.997 \\
$M_{2}$ & 0.518 \\
$S_{2}$ & 0.500 \\
\hline
\end{tabular}

1HD study by Gudmundsson (2011), we find that a nonlinear sliding law reproduces the general features of observations from the Rutford and other ice streams. Further work is needed to establish if a good quantitative agreement with available data can be achieved as well.

\subsection{Antarctic tides}

Ocean tides form an important boundary condition for ice flow and it is worth summarising some of their main general and geographical characteristics. Measurements of the tides beneath a floating ice shelf can be accomplished by satellite altimetry (Fricker and Padman, 2002; Padman et al., 2008), GPS data (King and Aoki, 2003; King et al., 2005) or gravity meters (Williams and Robinson, 1980; King et al., 2005). Of particular relevance are the two largest ice shelves: the Ross and Filchner-Ronne ice shelves. Conveniently, these two embayments are dominated by different tidal constituents allowing us to see how their responses change with different forcing periods.

The Weddell Sea tides are largely semi-diurnal with the $M_{2}$ and $S_{2}$ tidal constituents dominating and leading to a tidal range of up to $7 \mathrm{~m}$ (Robertston et al., 1998; King et al., 2011). Conversely, the Ross Sea is dominated by $O_{1}$ and $K_{1}$ tides with a smaller maximum peak-to-peak amplitude of $3 \mathrm{~m}$ and causing currents in excess of $1 \mathrm{~ms}^{-1}$ (Padman et al., 2002a, b). An overview of the main tidal constituents considered in this paper is given in Table 1.

\subsection{Overview of previous studies}

Since the discovery of tidal effects on ice streams (Harrison, 1993; Anandakrishnan and Alley, 1997; Engelhardt and Kamb, 1998; Bindschadler et al., 2003a, b; Anandakrishnan et al., 2003; Gudmundsson, 2006), the interpretation and understanding of the mechanisms and impacts has continued to develop. Initial measurements of tidal forcing on ice were limited to the surface of the ice shelves (Williams and Robinson, 1980) and the hinging zone where ice flexure occurs near the grounding line (Smith, 1991; Doake et al., 1987). In these regions, tidal effects can be simply described with analytical solutions and elastic beam theory (Holdsworth, 1969, 1977; Reeh et al., 2003). Measurements made by Anandakr- ishnan and Alley (1997) on the Kamb ice stream first showed that these effects were not limited to regions within a few ice thicknesses of the ocean boundary but could be transmitted far upstream.

The next step was the realisation that horizontal ice stream velocities could be modulated by the tides; much of the initial work focused on the Whillans ice stream (WIS) which was shown to exhibit a stick-slip behaviour resulting from vertical ocean tides (Anandakrishnan et al., 2003; Bindschadler et al., 2003b, a; Wiens et al., 2008; Winberry et al., 2009; Sergienko et al., 2009). This ice stream has mean annual speeds of greater than $300 \mathrm{~m} \mathrm{a}^{-1}$, but the majority of motion occurs in brief bursts over timescales less than $1 \mathrm{~h}$ followed by longer periods where the ice is almost stationary. The Whillans ice plain portion of the WIS is dominated by stick-slip motion, and the initiation of slip events strongly correlates with tides in the Ross Sea as accumulated stress is released.

Subsequently, it was observed that ice streams can show a long-period Msf response to a short-period tidal forcing, at both diurnal and semi-diurnal frequencies (Gudmundsson, 2006; Murray et al., 2007, Marsh et al., 2013). Of all the observed tidal effects on ice streams described above, it is arguably the long-period modulation in horizontal velocity, often far upstream of the grounding line, which has proven the most challenging to explain as it cannot be described by linear theory and requires a different mechanism.

One of the first attempts to explain the fortnightly variations in flow speed at Msf frequency observed on the Rutford ice stream was by Gudmundsson (2007), who suggested that they arise due to the nonlinear relationship between basal motion and basal shear stress. Due to this nonlinearity, the increase in basal velocity arising from an increase in shear stress is larger than the decrease from an equal but opposite reduction in shear stress. As a result of this imbalance over one tidal cycle, there is a net forward motion and over several tidal cycles the variation in tidal range leads to long-period modulation of flow speeds.

Murray et al. (2007) put forward a number of possible mechanisms, including Gudmundsson's model described above. They conclude that Gudmundsson's proposal cannot satisfactorily explain observations and a combination of processes are responsible. A partial ungrounding of the ice shelf from pinning points at high tides acts to increase velocity due to reduced basal resistive stress which is counteracted by increased back stress exerted by the lifted ice shelf (Heinert and Riedel, 2007) leading to a complex relationship between tidal range and horizontal velocities at different frequencies. The authors argue that none of the current theories can completely reproduce the difference in response between the solstice and equinox. Subsequent work by King et al. (2010), using the same data set as Murray et al. (2007), showed however that in fact the model presented by Gudmundsson (2007) could explain these observations and was consistent with a nonlinear sliding law with $m \approx 3$. 
(a)

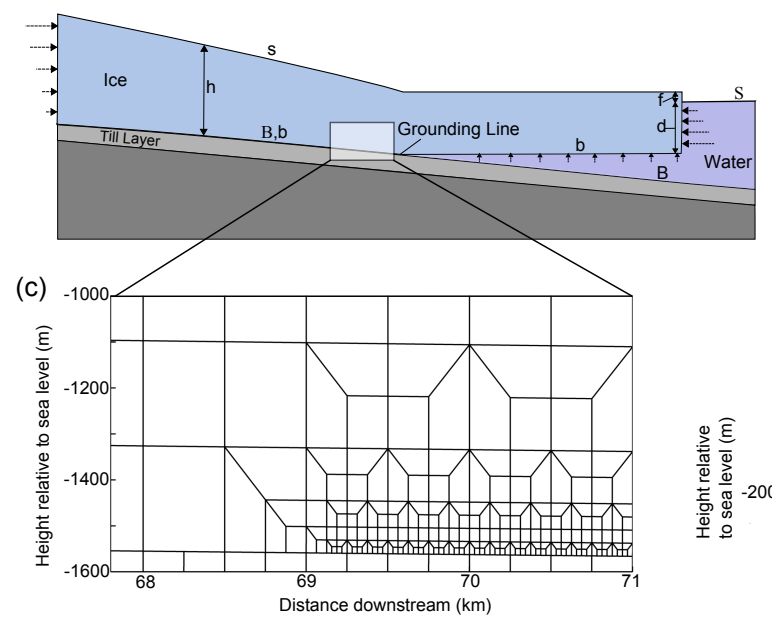

(b)

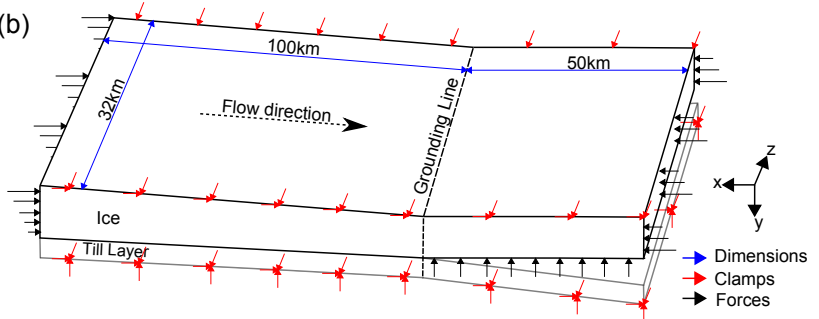

(d)

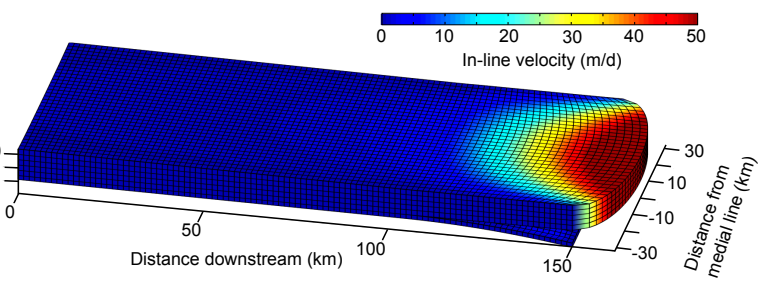

Figure 1. Model setup for 2-D (a, c) and 3-D (b, d) simulations. Panels (a) and (b) are schematic representations of the model domains while (c) and (d) show the model grid (panel (c) is zoomed in to show refinement near the grounding line). The 3-D grid in (d) has been vertically exaggerated by a factor of 4 .

A study by Doake et al. (2002) of the Brunt Ice Shelf has also been cited to explain tidal response in ice streams (Murray et al., 2007; Aðalgeirsdóttir et al., 2008). Variations in basal friction from sub-ice ocean currents driven by the tides were proposed as a mechanism to induce lateral movement of the ice shelf at tidal frequencies, and it was inferred that these motions would pull or push against the adjacent ice streams, thereby causing variations in horizontal velocities at the same frequency. Although this explanation for the motion of ice shelves has since been discounted (Brunt, 2008; Makinson et al., 2012; Brunt and MacAyeal, 2014), the back stress arising from these motions will still affect the ice streams, but this cannot explain longer-period frequencies which are not large in the ice shelf.

Another theory suggested by Aðalgeirsdóttir et al. (2008) is that basal melting near the grounding line, affecting subglacial pressure, might lead to some ice stream modulation at tidal frequencies as warmer water is transported to the grounding line by tidal currents. This idea seems unlikely to have any measurable impact on ice stream velocity however considering the typical magnitude of melting at daily or fortnightly timescales.

Gudmundsson (2007) first proposed the link to a nonlinear basal sliding law, and initial modelling efforts confirmed that a simple conceptual model including this process with $m=3$ in the sliding law could produce the observed fortnightly variations in horizontal velocity. An extension of this work, in which ice was modelled as a nonlinear viscoelastic medium and including all components of the equilibrium equation, further strengthened the argument (Gudmundsson, 2011). Work by King et al. (2011) showed that the same mechanism can reproduce ice stream velocity fluctuations from $4 \mathrm{~h}$ to 183 days observed in longer data series. A mod- elling study of the Bindschadler ice stream, forced primarily by diurnal rather than semidiurnal tidal constituents, further confirmed that a stress exponent $m>1$ is needed but found that a value of 15 provided a better fit to the observed velocities (Walker et al., 2012). Some of the differences may be due to different model assumptions; for example, the modelling study by Walker et al. (2012) solved a reduced set of equilibrium equations not including flexure stresses. According to the model by Gudmundsson (2011), flexure stresses can contribute to the tidal modulation in flow.

In addition to measurements of tidally induced surface velocity variations, observations of grounding line migration due to tides have been made using repeat-track laser altimetry of the Filchner-Ronne Ice Shelf with ICESat (Ice, Cloud, and land Elevation Satellite) (Brunt et al., 2011). Sayag and Worster (2013) explored this process using elastic beam theory and found that changes in overburden pressure of the ice over a tidal cycle could lead to a hydrological barrier that acts as a control on subglacial hydrology.

While the numerical flow-line study by Gudmundsson (2011) was capable of reproducing the key features observed in the data, there were a number of processes ignored which weaken the argument, primarily the lack of transverse effects and a fixed grounding line position. In this paper we aim to address these issues with two modelling studies, one including grounding line migration and one fully $3-\mathrm{D}$, and we show that a nonlinear basal sliding law can explain observed longperiod modulations in flow.

\section{Methods}

The ice stream/ice shelf model is based around a commercial full Stokes finite element analysis software MSC.Marc 
(MARC, 2013). While most of the results shown are for a fully 3-D model setup, simulations of a migrating grounding line were limited to a 2-D flow-line model due to computational limitations. An overview of the two model setups is shown in Fig. 1, where panels a and b are schematics of 2$\mathrm{D}$ and 3-D models respectively and panels $\mathrm{c}$ and $\mathrm{d}$ show the finite element grids. The field equations are the conservation of mass, linear momentum and angular momentum:

$$
\begin{aligned}
& \frac{D \rho}{D t}+\rho v_{q, q}=0, \\
& \sigma_{i j, j}+f_{i}=0, \\
& \sigma_{i j}-\sigma_{j i}=0,
\end{aligned}
$$

where $D / D t$ is the material time derivative, $v_{i}$ are the components of the velocity vector, $\sigma_{i j}$ are the components of the Cauchy stress tensor and $f_{i}$ are the components of the gravity force per volume. We use the comma to denote partial derivatives and the summation convention, in line with notation commonly used in continuum mechanics.

The rheological model is the same as that used by Gudmundsson (2011), and a more detailed description can be found there. Work by Reeh et al. (2003) showed that linear elastic models of ice were not adequate over tidal timescales, and they proposed instead the use of a linear viscoelastic Burgers model of ice rheology. Following the arguments made in Gudmundsson (2011) we use a nonlinear Maxwell model (consisting of a viscous damper and elastic spring connected in series) which has a close agreement to more complex Burgers model at the relevant timescales.

The Maxwell rheological model relates deviatoric stresses $\tau_{i j}$ and deviatoric strains $e_{i j}$ :

$\dot{e}_{i j}=\frac{1}{2 G} \stackrel{\nabla}{\tau}_{i j}+A \tau^{n-1} \tau_{i j}$

where $A$ is the rate factor, $\stackrel{\nabla}{\tau}$ denotes the upper-convected time derivative, $G$ is the shear modulus

$G=\frac{E}{2(1+v)}$,

$v$ is the Poisson's ratio and $E$ is the Young's modulus. The deviatoric stresses are defined as

$\tau_{i j}=\sigma_{i j}-\frac{1}{3} \delta_{i j} \sigma_{p p}$

and the deviatoric strains as

$e_{i j}=\epsilon_{i j}-\frac{1}{3} \delta_{i j} \epsilon_{p p}$,

where $\sigma_{i j}$ and $\epsilon_{i j}$ are the stresses and strains, respectively.

The model results presented here use a Young's modulus of between 1 and $3 \mathrm{GPa}$ and a Poisson's ratio of 0.45 . A number of runs were performed for a range of different values, but it was found that the choice of values for these parameters did not affect the results qualitatively.

\subsection{Contact}

The contact option of MSC.Marc is used to simulate the detachment and migration of the grounding line. The ice and till layer are defined as separate deformable contact bodies such that, during each incremental position, the software checks whether every potential contact node from each body is near a contact segment. A contact segment is either an edge of a 2D deformable body or the face of a 3-D deformable body. In order to maximise computational efficiency, the software first defines a bounding box which quickly determines whether a node is near a segment; if the node falls within this box, more sophisticated techniques are used to find the exact status of the node. A contact tolerance is defined for each surface and if a node is within this tolerance region, it is considered to be in contact; if the node has passed through the tolerance range, it is considered to have penetrated and a procedure is invoked to avoid this penetration.

Once two contact segments come into contact, a "glue" tying condition is applied so that there is no relative tangential motion between them. In the fully 3-D case this is as far as contact goes; the two contact bodies remain glued throughout the procedure and the ice flows primarily by deforming the till layer. For simulations in 2-D, where the grounding line migrates, the glue may separate, allowing the grounding line to move back and forth with the time-varying ocean pressure. For the migration simulations presented here, the glue separation criterion is simply that the two bodies are released when the tensile force between them exceeds a certain stress. In reality, it would be expected that, as soon as tensile forces are greater than zero, the ice would lift and the grounding line would migrate; however, for numerical purposes, the separation stress is defined as a very small number to stop numerical chattering between segments. This avoids a situation where tiny variations in stresses between time increments cause two contact segments to repeatedly change in and out of contact at high frequency.

\subsection{Boundary conditions}

Along the ice-bed interface upstream of the grounding line, a Weertman sliding law is used of the form

$\boldsymbol{v}_{\mathrm{b}}=c\left|\mathbf{t}_{\mathrm{b}}\right|^{m-1} \mathbf{t}_{\mathrm{b}}$,

where $\boldsymbol{v}_{\mathrm{b}}$ is the basal motion (considered here to be the sum of sliding and till deformation), $\mathbf{t}_{\mathrm{b}}$ is the basal traction

$\mathbf{t}_{\mathrm{b}}=\sigma \hat{\mathbf{n}}-\left(\hat{\mathbf{n}}^{T} \cdot \sigma \hat{\mathbf{n}}\right) \hat{\mathbf{n}}$,

where $\hat{\mathbf{n}}$ is a unit vector normal to the ice. The parameters $c$ and $m$ in Eq. (8) both have large effects on model results, where $c$ is referred to as basal slipperiness and reflects local conditions at the bed. This value is expected to change depending on the region of interest, and in this study it is tuned to produce realistic surface velocities. The stress exponent $m$ 
is the main focus of the modelling work presented here, and previous modelling studies have used values ranging from 1 to infinity. Although the Weertman sliding law (first proposed by Weertman, 1957) has been and continues to be used extensively in modelling basal motion of glaciers, and in spite of the importance that the stress exponent plays in modelling large-scale ice masses, there is still debate as to its value and values ranging from 1 to infinity are commonly used in modelling studies of the flow of large ice masses (e.g. Cuffey and Patterson, 2010; Walker et al., 2012).

Along the ice-ocean interface beneath the ice shelf, downstream of the grounding line, water pressure $p_{\mathrm{w}}$ acts normal to the ice surface:

$p_{\mathrm{w}}=\rho_{\mathrm{w}} g(S(t)-z)$,

where $\rho_{\mathrm{W}}$ is the water density, $g$ is gravitational acceleration and $S$ is the water surface. The tidal forcing in the model is introduced by making $S$ an appropriate function of time with amplitude and period corresponding to local tidal constituents (described in Sect. 1.1). The boundary condition is implemented as a linear elastic spring such that the pressure normal to the ice is given by

$p_{\mathrm{w}}=k\left(z+z_{0}\right)$,

where $k$ is the spring constant, $z_{0}$ the offset and $z$ the position of the ice-ocean boundary. This is a convenient method for determining flotation within the software as it tends to converge faster than applying a direct vertical ocean pressure to the underside of the ice. Substituting in $k=-\rho_{\mathrm{w}} g$ and $z_{0}=-S(t)$ gives Eq. (10). The result is that during high tide the maximum force is applied under the floating portion of the ice, lifting it vertically by the same distance as the tidal amplitude except for around the hinging zone.

At the upstream boundary of the model, a pressure $p$ is applied normal to the ice:

$p=\rho_{i} g(s-z)$,

where $s$ is the ice surface and $\rho_{i}$ is the ice density which is assumed to be constant $\left(917 \mathrm{~kg} \mathrm{~m}^{-3}\right)$.

At the downstream boundary of the model, we assume the ice shelf terminates at a calving front and apply a normal pressure

$p=\rho_{\mathrm{w}} g(S-z)$,

for $z<0$. For ice floating above water at the calving front $z>0$, the boundary condition is simply $p=0$. Although the assumption that the ice shelf is only $50 \mathrm{~km}$ long is out by an order of magnitude for many of the large ice streams outflowing from Antarctica, it can be considered valid because the region of interest around and upstream of the grounding line is far enough away and fairly insensitive to the choice of boundary condition.

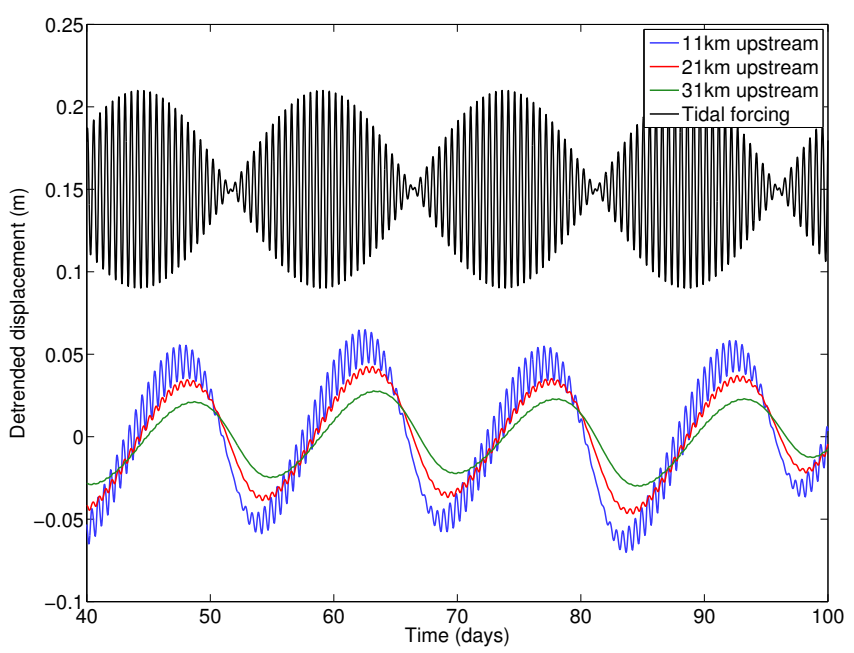

Figure 2. Detrended in-line displacements at 11, 21 and $31 \mathrm{~km}$ upstream of the grounding line for the 3-D model run using an idealised ice stream geometry. The tidal forcing is also shown, scaled down by a factor of 100 and shifted vertically.

In the fully 3-D simulations, additional boundary conditions are applied which are not required for the 2-D case. At both lateral boundaries of the model, the horizontal velocity component $v=0$ and one side wall has the additional constraint that $u=0$; however, vertical velocities are not constrained in this way anywhere. These additional boundary conditions replicate a situation where one margin of the ice stream is bounded by topography or ice with negligible velocity (no-slip) and the other side can be considered to be the ice stream medial line (free-slip). In this way, although the model domain is only $32 \mathrm{~km}$ wide, the solution is symmetrical and so the ice stream being modelled is in fact $64 \mathrm{~km}$ wide.

\subsection{Element discretisation}

In 2-D simulations an isoparametric, eight-node quadrilateral element was used, optimised for plane strain applications. Biquadratic interpolation functions are used to represent coordinates and displacements, and thus the strains have a linear variation within the element. The dimensions of the elements varied considerably from $>1 \mathrm{~km}$ along much of the ice shelf to $30 \mathrm{~m}$ around the grounding line. A grid refinement of $150 \mathrm{~m}$ was initially used around the grounding line, but this was found to be insufficient and so the elements were subsequently reduced to the lower value quoted above. For full 3-D simulations an isoparametric, 20-node distorted brick was used with full integration, where each face consisted of eight nodes with the same layout as the 2-D element described above. Dimensions vary considerably less than the 2-D geometry and are typically $1 \mathrm{~km}, 400 \mathrm{~m}$ and $2 \mathrm{~km}$ along the $x, y$ and $z$ planes, respectively. 


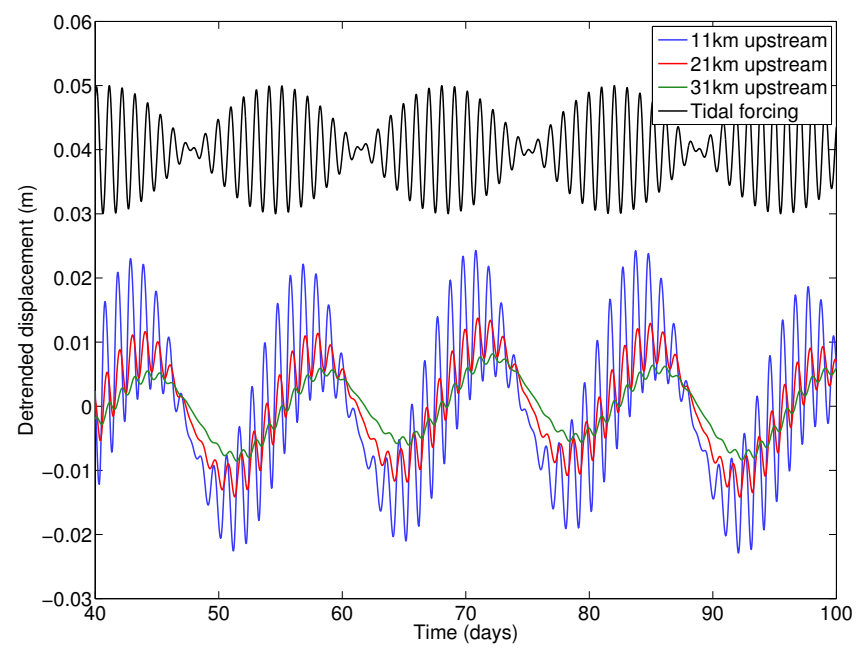

Figure 3. Detrended in-line displacements at 11, 21 and $31 \mathrm{~km}$ upstream of the grounding line for the 3-D model run using an idealised Siple coast geometry. The tidal forcing is also shown, scaled down by a factor of 100 and shifted vertically.

\section{Results}

\subsection{3-D results}

Numerical simulations initially focused on fully 3-D full Stokes modelling of the response of an ice stream to tidal forcing. Figure 2 shows modelled horizontal displacements along the medial line of the ice stream 11, 21 and $31 \mathrm{~km}$ upstream of the grounding line. The tidal forcing consisted of $M_{2}$ and $S_{2}$ tidal constituents with amplitudes comparable to those around the Rutford ice stream (RIS) and is plotted alongside the ice stream response (scaled down by a factor of 100 and shifted vertically).

The model geometry that produced these results had a domain as shown in Fig. 1, with ice thicknesses and slopes representing an idealised configuration which generally compares to those found on a typical ice stream. A stress exponent of $m=3$ was used. Following the methods in previous studies, the basal slipperiness was changed in order to produce surface velocities of about $1 \mathrm{~m} \mathrm{~d}^{-1}$ (Gudmundsson, 2007, 2011; King et al., 2010; Walker et al., 2012).

The detrended horizontal displacements in Fig. 2 show that the ice stream response, when forced with semi-diurnal tidal periods, is dominated by the Msf period (14.76 days). Furthermore, this effect becomes more pronounced higher upstream such that the semi-diurnal modulation of displacements disappears almost completely by $30 \mathrm{~km}$ upstream of the grounding line. These results match those of Gudmundsson (2011) and strengthen the hypothesis that the long-period modulation of ice stream velocities is a result of a nonlinear basal sliding law. When the model was forced with a stress exponent of 1 , no long-period effects occurred.
Figure 3 shows the results of a similar experiment which used a geometry and tidal forcing similar to those of the Siple coast ice streams rather than the RIS. The tide in this region is dominated by diurnal $\left(K_{1}\right.$ and $\left.O_{1}\right)$ rather than semi-diurnal constituents and with lower amplitudes than around the RIS. This time the ice stream responds to diurnal forcing with Mf frequency modulation in horizontal detrended displacements; however, it does not dominate as strongly as the Msf did for semi-diurnal forcing. Note that the scale is different and the Mf signal $31 \mathrm{~km}$ upstream of the grounding line has an amplitude of only $\sim 1 \mathrm{~cm}$. This amplitude is too small to be measurable using current GPS techniques. We therefore conclude that Mf amplitudes on the Siple coast ice streams are expected to be small and difficult to measure, and about an order of magnitude less than the Msf signal found on the Filchner-Ronne ice streams.

\subsection{2-D results}

In order to investigate the effect of a migrating grounding line on an ice stream's response to tidal forcing, a 2-D geometry was used with refinement near the grounding line as depicted in Fig. 1c. An initial control run used the same ice thickness and slopes as the 3-D case, but with a slightly smaller domain extending $80 \mathrm{~km}$ upstream and $40 \mathrm{~km}$ downstream of the grounding line, respectively. In this initial simulation the two contact bodies were not allowed to separate and thus the grounding line would not migrate, as in the 3-D case. Since grounding line migration depends on the slope of the bed at the grounding line, with smaller slopes leading to larger migration distances, simulations with a migrating grounding line were done for various bed slopes and compared with the non-migrating case. To keep other properties as similar as possible, the slope was only changed in a region near the grounding line and the majority of the bed had the same slope as other simulations.

Grounding line migration for the different slopes is asymmetrical as demonstrated in Fig. 4. The comparison between tidal forcing and grounding line position shows that at high tide the grounding line retreats considerably further than during low tide, and the asymmetry is slightly stronger for steeper slopes. Since the distance by which the grounding line migrates is very sensitive to geometry, which is represented here by a constant shallow slope but in reality is probably much more complex, these results should not be considered as an exact study of the tidally modulated grounding line migration of an ice stream. In spite of this, the asymmetrical nature of the migration is expected, as shown in a novel study of this process (Tsai and Gudmundsson, 2014), and thus is a possible additional source of nonlinearity that could help produce the large Msf modulation observed on a number of ice streams.

Due to the difficult nature of the grounding line problem, at some points in the simulation isolated nodes or groups of nodes occasionally change in or out of contact some distance 


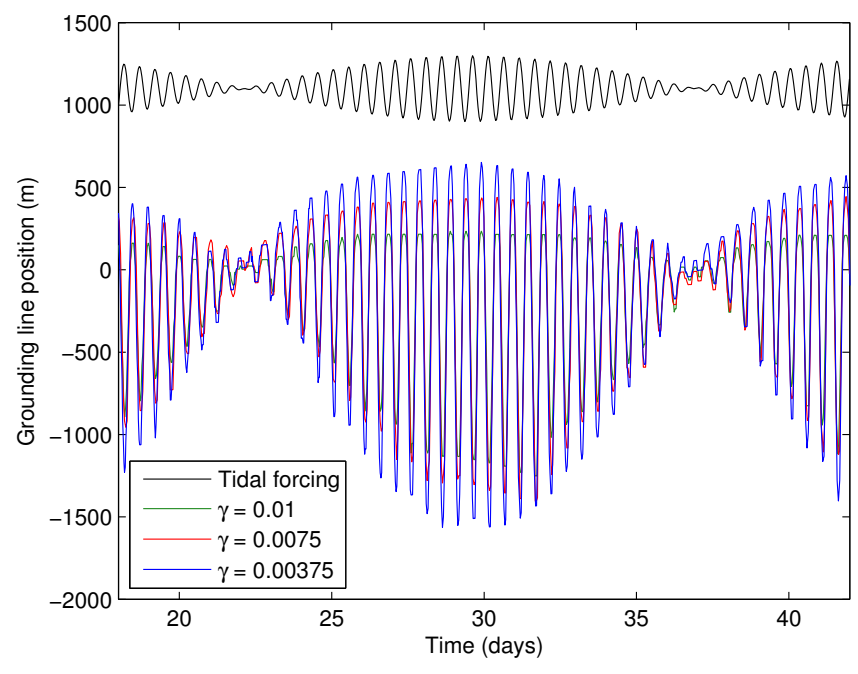

Figure 4. Comparison of change in grounding line position from the mean location, for various slopes $(\gamma)$ as a function of time. The tidal forcing is also shown (solid black line), scaled up and shifted vertically.

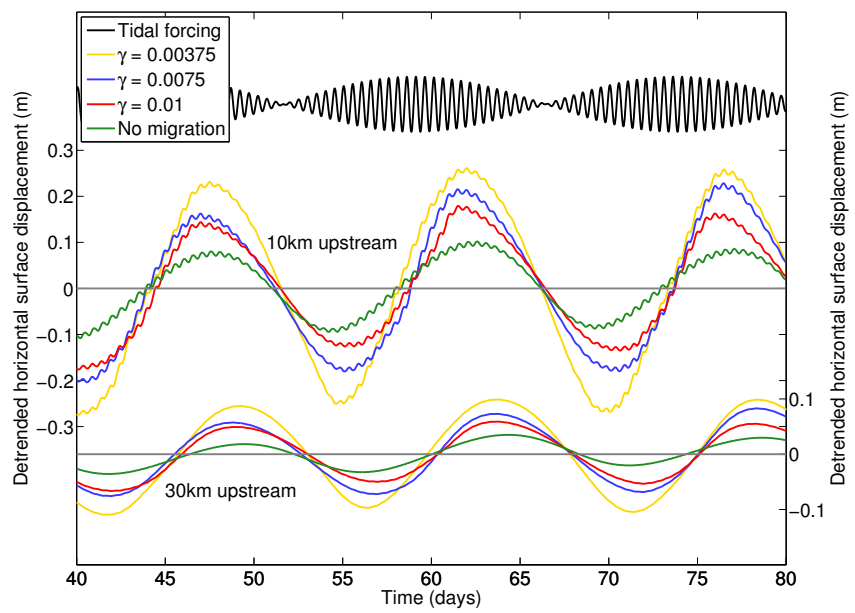

Figure 5. Comparison of detrended in-line displacements for geometries with different slopes. The upper plot shows the tidal forcing (scaled down by a factor of 100 and shifted vertically for clarity). The middle plot shows in line displacements $10 \mathrm{~km}$ upstream of the grounding line with and without migration, and the lower plot shows the same $30 \mathrm{~km}$ upstream.

away from the expected grounding line position. As a result of this complication, grounding line position as plotted in Fig. 4 is defined as the point along the base of the ice where, travelling upstream, the ice makes contact with the bed for at least five consecutive nodes.

Results showing the comparison between different migrating cases and the fixed grounding line run are shown in Fig. 5. The uppermost curve is the semi-diurnal forcing scaled down and shifted vertically. Beneath this are four curves showing detrended horizontal surface displacement $10 \mathrm{~km}$ upstream (a)

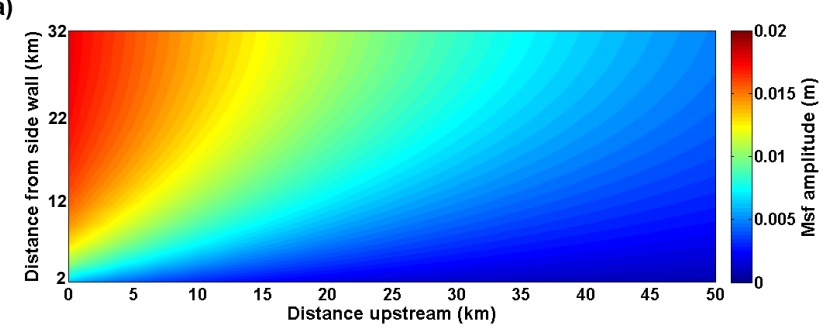

(b)

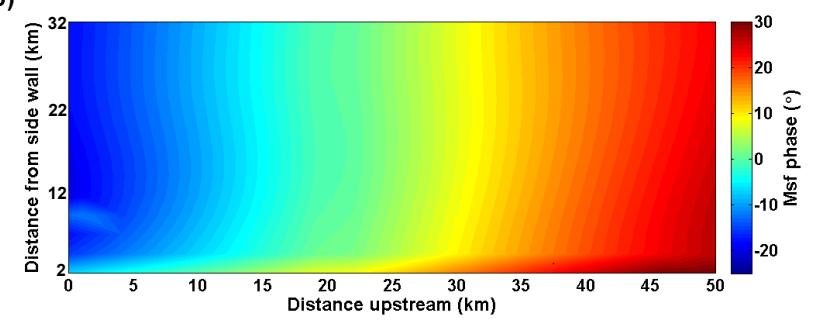

Figure 6. Plots showing amplitude (a) and phase (b) of the Msf tidal constituent based on tidal analysis of detrended horizontal surface displacement.

of the grounding line for the no breaking case and slopes ranging from $\gamma=0.00375$ to 0.01 . The final lowermost set of curves show the same but $30 \mathrm{~km}$ upstream. These results show that adding a migrating grounding line does not affect the main results demonstrated in this study and previous work and qualitatively the long-period modulation is the same as for a non-migrating case. We find that runs with smaller slopes and hence larger migration distances produce a stronger Msf signal upstream of the grounding line, with the smallest slope producing displacements more than twice as large as in the fixed grounding line run. This is a result of the added nonlinearity that arises due to the asymmetry of the grounding line migration.

\subsection{Tidal analysis}

A run using an identical model geometry and parameters as that shown in Fig. 2 was done but including values for all major tidal constituents (those with amplitudes greater than $5 \%$ of the $M_{2}$ ) around the RIS with amplitudes obtained from the CATS2008 tidal model (Padman et al., 2008). Subsequently, tidal analysis was done on these results using the t_tide MATLAB package (Pawlowicz et al., 2002). We choose this slightly different forcing in order to show that the Msf signal arises from a realistic tidal forcing as well as the more simplified forcings used previously. Figure 6 shows the calculated amplitude (panel a) and phase (panel b) of the Msf tidal constituent upstream of the grounding line. The phase is almost constant apart from very near to the clamped side wall whereas amplitude decreases gradually and has not reached an apparent maximum even $30 \mathrm{~km}$ away from the boundary.

As with previous studies we find that the nonlinearity of the tidal response leads to a shift in mean velocity 
(Gudmundsson, 2011; King et al., 2010). For the simulation described above, forcing the domain with tides was found to increase the mean velocity by about $3 \%$ when compared to a run with no tides. This represents a similar or slightly smaller effect than that seen in previous work; a reduction may be expected since the model presented here includes lateral effects.

Since the model being used is fully three-dimensional, it is worth examining how the characteristics of the ice stream vary laterally. Velocities do not vary considerably in the lateral direction for the central half of the ice stream but decay rapidly approaching the sidewall, reaching $20 \%$ of the medial line value $2 \mathrm{~km}$ from the fixed boundary. The diagonal components of the stress tensor vary only slightly laterally; however, shear stress does change as would be expected. A convenient measure of the shear stress is the maximum principal shear stress which is constant in the middle of the ice stream but then increases linearly towards the boundary, reaching a maximum that is almost double the medial line stress.

\subsection{Linearised experiments}

The model presented here provides an opportunity to investigate the effects of different forcing frequency on ice stream flow and stress transmission upstream of the grounding line. Figure 7 shows the change in amplitude upstream of a grounding line for a simple sinusoidal boundary forcing with a range of frequencies. For these simulations, the frequencies used at the boundary were not of a tidal nature; instead, the ocean boundary was forced with a systematic spread of periods to get a clearer picture of the effect on an ice stream. In addition, ice rheology and the flow law were linearised in order to make a comparison between our results and the expected response from simplified equations (see the discussion for more details). Amplitude is normalised and plotted on a log scale for clarity. Both amplitude and phase are shown to depend on the frequency of the forcing. In all cases the horizontal velocity amplitude response decays exponentially; however, at short forcing periods the rate of decay is a function of the period while for longer forcing periods the curves converge to one solution. A run was also done with a forcing period of 32 days but it has not been plotted here for the sake of clarity since it lies on top of the curve of $T=16$.

\section{Discussion}

Previous modelling studies have successfully reproduced long-period modulation of ice stream flow by forcing their models with only semi-diurnal and diurnal tidal constituents and using a nonlinear basal sliding law (Gudmundsson, 2007; King et al., 2010; Gudmundsson, 2011; Walker et al., 2012). This study demonstrates that including lateral effects

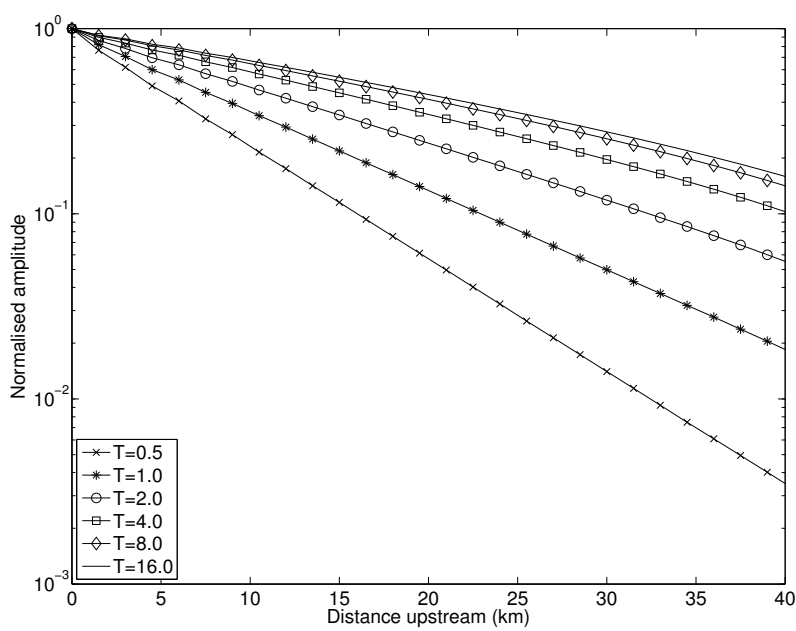

Figure 7. Normalised amplitude response to various periods (in days) of boundary forcing as a function of distance upstream as calculated by the model. Model parameters used were $A=4.0^{-7} \mathrm{~d}^{-1} \mathrm{kPa}^{-1}, m=1, n=1, E=3 \mathrm{GPa}, v=0.45$ and a value for the rate factor in the till to produce surface velocities of $1 \mathrm{~m} \mathrm{~d}^{-1}$. Note that amplitude is plotted on a log scale.

and grounding line migration does not alter this result and that the effect on ice stream flow is qualitatively the same, confirming the hypothesis that a sliding law with $m>1$ is required.

For an idealised ice stream geometry, the model produces a clear Msf frequency (Fig. 2) matching observations made in this area. When forcing the model with a geometry more typical of the Siple coast and diurnal tides, the long-period modulation remains but some features of the response are quite different (see Fig. 3). Firstly, the long-period response is at Mf frequency, as would be expected from a combination of $K_{1}$ and $O_{1}$ tidal constituents. In addition, the diurnal signal remains relatively strong even far upstream of the grounding line, but the overall amplitudes for both long and short-period motion are much smaller than the previous case. The amplitude of only $\sim 1 \mathrm{~cm}$ is too small to be measurable using current GPS techniques. We therefore conclude that Mf amplitudes on the Siple coast ice streams are expected to be small and difficult to measure, and about an order of magnitude less than the Msf signal found on the Filchner-Ronne ice streams.

Simulations in which the grounding line could migrate back and forth with the tide give a long-period modulation in flow that is qualitatively the same as those without migration (Fig. 5). Changing the slope of the bed near the grounding line in order to allow for more or less migration alters the magnitude of the Msf response only, and the transmission of semi-diurnal forcing upstream appears to be unaffected.

Based on the results of the linearised model shown in Fig. 7, it is clear that the different responses at semi-diurnal, diurnal, Msf and Mf frequencies are expected. When the 
model is forced systematically with a range of different periods, a clear relationship appears between the stress-coupling length scale of the signal amplitude upstream of the grounding line and the ocean boundary condition period. Deviations from the mean horizontal flow decay exponentially for periods of a few days. For longer periods, this relationship breaks down and appears to be approaching a limit at $T=16$ days. The cause of this lies in the viscoelastic rheology of the model; at short loading periods the ice behaves purely elastically but once this loading period passes a certain threshold the ice is dominantly viscous, at which point loading period has no effect. We can relate this threshold to the effective relaxation time of the Maxwell model

$\lambda=\frac{\eta}{G}$,

where

$\eta=\frac{\tau^{1-n}}{2 A}$.

Since $n=1$ in these linearised runs, this is easily solved and gives a timescale of 1.2 days which matches well with the model results described above.

It is also possible to estimate the expected stress-coupling length scale in order to compare it with our results. We follow a similar method to Walters (1989), who adds small variations in velocity to the SSA (shallow shelf approximation) to derive a length scale, but carry this further by making velocity a function of period.

We can simplify the SSA for the linearised homogenous case as

$4 \partial_{x}\left(\eta h \partial_{x} u\right)-\frac{u}{c}=0$,

where $h$ is ice thickness, $c$ is bed slipperiness and $u$ is ice velocity. The bed slipperiness is extracted from the model using the linearised Weertman sliding law (see Eq. 8 with $m=1$ and where $t_{b}$ and $v_{b}$ are model outputs). Along with this equation we must make use of Eq. (4), which contains both the viscous and elastic components of deformation. Assuming $\eta$ and $h$ are not functions of $x$, adding a small periodic variation in the velocity of amplitude $\hat{u}$ such that

$u=\bar{u}+\hat{u} e^{i(k x-\omega t)}$

and substituting into Eq. (16), we can derive an expression for $k$ :

$k^{2}=\frac{i \omega \lambda-1}{4 h \eta c}$,

where $\omega=\frac{2 \pi}{T}, T$ is the forcing period and $\lambda$ is the relaxation time (Eq. 14). Since $k^{2}$ is a complex number that can be expressed as $\alpha+i \beta$, we find its roots to be $\pm(\gamma+\delta i)$ where

$\gamma=\sqrt{\frac{-1+\sqrt{1+(\omega \lambda)^{2}}}{8 h c \eta}}$ and

$\delta=\sqrt{\frac{1+\sqrt{1+(\omega \lambda)^{2}}}{8 h c \eta}}$.

Substituting the complex expression for $k$ into Eq. (17), it becomes apparent that the velocity variation $\hat{u}$ has a decay part $e^{-\delta x}$ and a wave part $e^{i(\gamma x-\omega t)}$. The relevant length scale is therefore given by

$L=\frac{1}{\delta}$

and the phase velocity is

$v_{p}=\frac{\omega}{\gamma}$.

The length scale $L$ determines how a perturbation in any of the field variables (i.e. velocity, strain, stress) decays with distance. This effect is due to transmission of stresses within the viscoelastic body, which in our model is instantaneous (in reality limited by the seismic velocity of ice and till). The length scale is, hence, not related to mass redistribution of ice with time that gives rise to a number of further length scales (e.g. Gudmundsson, 2003). Here we refer to $L$ as the (viscoelastic) stress-coupling length scale.

By taking only the elastic or viscous contributions to the deviatoric strains in Eq. (4), it is possible to derive a length scale for a purely elastic or viscous material. The purely elastic length scale is

$L_{e}=\sqrt{\frac{4 h G c T}{\pi}}$

and the purely viscous length scale is

$L_{v}=\sqrt{4 \eta h c}$.

Crucially, a time derivative only appears in the elastic contribution to deviatoric strain; it is from this that the stresscoupling length scale becomes a function of period whereas, for a purely viscous material, there is no dependence on forcing period.

The two limiting cases appear in Eq. (20) such that as $\omega \rightarrow 0$ (for very long periods), it simplifies to the purely viscous length scale, and for $\omega \gg 1$ the dependance on viscosity disappears to give the purely elastic length scale. The derivations of these stress-coupling length scales are simple for a Maxwell rheology because elastic and viscous strains can be related by $\varepsilon_{\text {total }}=\varepsilon_{\text {viscous }}+\varepsilon_{\text {elastic }}$.

A plot comparing forcing period with the three linearised length scales calculated above, along with the modelled length scale, is shown in Fig. 8a (black lines). This shows that the modelled length scale agrees well with the elastic solution at short forcing periods, then deviates at longer periods approaching an asymptote for $T \gg \lambda$. The derived full 
(a)

(b)
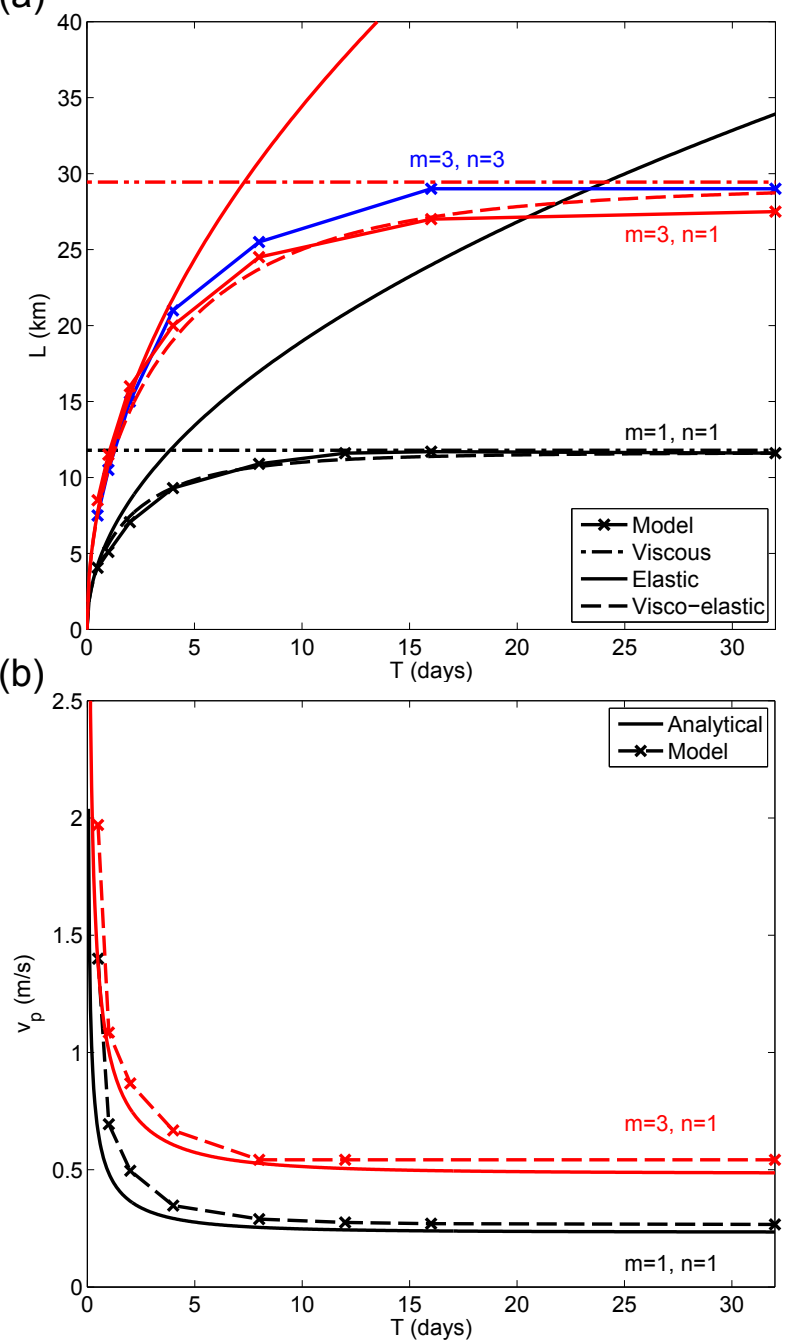

Figure 8. Comparison of analytical solutions for stress-coupling length scale (panel a) and phase velocity (panel b) with model results. Solutions and results for linearised runs are shown in black, semi-nonlinear runs in red and fully nonlinear runs in blue. In panel (a) the solid and dot-dashed lines are the purely viscous and elastic length scales respectively as derived from the linearised SSA, and the dashed line is the combined viscoelastic response. The modelled length scales are the solid lines marked with crosses representing a model run for that given loading period. In panel (b) the phase velocity in the model (dashed line) was calculated by a least squares fit and compared to the analytical solutions.

viscoelastic solution provides a good fit with the modelled results.

Walters (1989) fitted data from an Alaskan tidewater glacier on amplitude decay with distance from grounding line to a purely viscous version of the stress-coupling scale similar in form to Eq. (23). While the comparison made in that study provided a good agreement to observations, the author effectively chooses a value of $\eta$ that produced best fit to data, and since the decay is known to be exponential, it is not unexpected that a good fit is obtained. Regardless, the same method cannot be used for forcing periods similar to or smaller than the Maxwell timescale. As has been shown, the stress-coupling length scale at these periods strongly depends on the period and either the purely elastic or full viscoelastic stress-coupling length scale should be used.

A length scale can also be calculated for a nonlinear sliding law where $m \neq 1$. In this case, the basal stress term in Eq. (16) is raised to the power of $\frac{1}{m}$ and the length scale becomes

$L=\sqrt{\frac{8 h \eta m c^{1 / m} \bar{u}^{1-1 / m}}{1+\sqrt{1+(\omega \lambda)^{2}}}}$.

It is easy to see that this equation reduces to the linear length scale equation for $m=1$, but for $m=3$ the effect is an increase in the stress-coupling length scale compared to the linearised case. The model was run again with the same range of forcing periods as discussed above for two new scenarios: (a) a nonlinear sliding law but retaining the assumption of linear homogeneous rheology $(m=3, n=1)$ and (b) a nonlinear sliding law and nonlinear rheology $(m=3, n=3)$. Model results for the two new scenarios are plotted in red and blue for cases (a) and (b) respectively in Fig. 8 along with the derived nonlinear stress-coupling length scale given in Eq. (25).

As expected, the length scales for the case where $m=3$ and $n=1$ are considerably longer than the fully linearised runs and agree well with the derived nonlinear stresscoupling length scale. For the range of parameters explored, the change in length scale from $m=1$ to $m=3$ was much greater than the change from $n=1$ to $n=3$, suggesting that the assumption of linear rheology in Eq. (25) does not have a large effect. Note that a similar study looking at stress transmission for a narrower ice stream configuration than the one presented here showed much smaller length scales and proposes an alternative mechanism for stress transmission (Thompson et al., 2014).

Phase velocities were calculated for each forcing period for linearised (black line) and semi-nonlinear (red line) cases using a least squares fit, and the results are compared with the analytical solutions in Fig. 8b. The phase velocities calculated from the model agree reasonably well with the analytical solutions, although they appear to be slightly overestimated particularly at short forcing periods. Some difference might be expected however since the equations have been derived from the SSA and the model is solving the full Stokes solution. As with the stress-coupling length scale, the phase velocities for $m=3$ are increased compared to $m=1$.

Previous studies cite a single value for the phase velocity of tidal forcing travelling upstream of an ice stream grounding line, but these results show that phase velocity strongly depends on the forcing period up to a limit where $T \gg \lambda$. The semidiurnal tidal constituents have a period of 0.5 days and based on these results have a phase velocity of $1.45 \mathrm{~ms}^{-1}$ whereas the longer-period Mf and Msf constituents have 
a period of 14 days and would have a phase velocity of $0.27 \mathrm{~ms}^{-1}$, over 5 times less. The range of values we find for phase velocity agree with the range of values typically found in the literature; however, since most of these studies make it unclear how it has been calculated or which constituent they are considering, it is difficult to make a direct comparison.

The fact that the results shown in Fig. 7 match the derived analytical stress-coupling length scale helps to verify our numerical model and gives increased confidence in the accuracy of our numerical results. The analytical solution also shows, for the first time, directly how phase and amplitude of the tidal response vary with distance upstream from the grounding line. This result also emphasises once again the importance of a correct value for $m$ in getting realistic stress transmission along an ice stream.

\section{Conclusions}

The numerical model presented here finds that a nonlinear sliding law with $m=3$ produces long-period modulation in ice stream flow, supporting the conclusions of previous work, and the inclusion of sidewalls and a migrating grounding line does not qualitatively change this result. Forcing the model with $M_{2}$ and $S_{2}$ tidal constituents reproduces the Msf surface velocity signal whereas a diurnal forcing of $K_{1}$ and $O_{1}$ gives a different response with smaller long-period modulation at Mf frequency, in both cases agreeing with GPS observations of ice streams subjected to these tidal forcings.

Upon closer inspection of model results, we find a stresscoupling length scale that depends on the forcing period at timescales less than the Maxwell relaxation time. Comparing length scale obtained from the linearised model with the calculated length scales for a purely viscous or elastic response shows that the ice stream responds elastically at short forcing periods only (e.g. diurnal and semi-diurnal constituents). Once the forcing period is much larger than the relaxation time, the stress-coupling length scale approaches that of a purely viscous medium (e.g. Msf and Mf constituents). This result holds for the nonlinear model, but both phase velocities and length scale are found to increase considerably for $m=3$.

An ice stream's response to an external forcing is a function of the period of that forcing if the forcing period is short compared to the relaxation time. Ice streams are generally modelled as either viscous or elastic media. These results reflect that, over short timescales, an ice sheet behaves purely elastically and viscous effects can be neglected. Conversely, when short-term response can be ignored and changes are occurring over long timescales a purely viscous model may be suitable. Dependency on forcing period is an important consequence of an ice stream's viscoelastic rheology often missed by authors quoting only one value for measurements such as the propagation of stress upstream.
This study is limited in that, due to computational constraints, running the model in 3-D and allowing the grounding line to migrate at the same time was not feasible; however, these two effects can be considered separate and the combination of the two is not expected to change the results. In addition, the model geometry is an idealised form with a simple profile meaning the outputs cannot be directly compared to any one particular ice stream but must be considered as a generalised qualitative result.

We have further demonstrated how sensitive the response of ice streams to tides is on basal conditions. Despite only focusing on the general qualitative aspects of available measurements, we are nevertheless able to confidently conclude that a linear sliding law is not consistent with observations. Although it may appear that we have not been able to constrain the form of the sliding law very tightly, and clearly much more work remains to be done, we know of no other type of field observation or modelling work done to date that has allowed firm conclusions of this type to be made. This is despite decades spent in extracting information about basal control on motion by various other means. Therefore, currently the most successful and the most promising approach to study controls on basal motion is through modelling and measurements of tidally induced perturbations in flow.

Acknowledgements. We would like to thank Andrew Bell (MSC Software) for invaluable help with the MSC.Marc model. This study is part of the British Antarctic Survey Polar Science for Planet Earth Programme. Funding was provided by the UK Natural Environment Research Council through grant NE/J/500203/1 (SHRR PhD studentship). J. A. M. Green acknowledges funding from the Climate Change Consortium for Wales and from the NERC, grant NE/F014821/1 (Advanced Fellowship).

Edited by: E. Larour

\section{References}

Ađalgeirsdóttir, G., Smith, A. M., Murray, T., King, M. A., Makinson, K., Nicholls, K. W., and Behar, A. E.: Tidal influence on Rutford Ice Stream, West Antarctica: observations of surface flow and basal processes from closely-spaced GPS and passive seismic stations, J. Glaciol., 54, 715-724, 2008.

Alley, R. B., Clark, P. U., Huybrechts, P., and Joughin, I.: Ice-sheet and sea-level changes, Science, 310, 456-460, 2005.

Anandakrishnan, S. and Alley, R.: Tidal forcing of basal seismicity of ice stream C, West Antarctica, observed far inland, J. Geophys. Res., 102, 15813-15196, 1997.

Anandakrishnan, S., Voigt, D. E., and Alley, R. B.: Ice stream D flow speed is strongly modulated by the tide beneath the Ross Ice Shelf, Geophys. Res. Lett., 30, 1361, doi:10.1029/2002GL016329, 2003.

Bindschadler, R. A., King, M. A., Alley, R. B., Anandakrishnan, S., and Padman, L.: Tidally controlled stick-slip discharge of a West Antarctic Ice Stream, Science, 301, 1087-1089, 2003a. 
Bindschadler, R. A., Vornberger, P. L., King, M. A., and Padman, L.: Tidally driven stickslip motion in the mouth of Whillans Ice Stream, Antarctica, Ann. Glaciol., 36, 263-272, 2003b.

Brunt, K. M.: Tidal motion of the Ross Ice Shelf and its interaction with the Siple Coast ice streams, Antarctica, Ph.D. thesis, University of Chicago, USA, 2008.

Brunt, K. M. and MacAyeal, D. R.: Tidal modulation of ice-shelf flow: a viscous model of the Ross Ice Shelf, J. Glaciol., 60, 500508, 2014.

Brunt, K. M., King, M. A., Fricker, H. A., and Macayeal, D. R.: Flow of the Ross Ice Shelf, Antarctica, is modulated by the ocean tide, J. Glaciol., 56, 157-161, 2010.

Brunt, K. M., Fricker, H. A., and Padman, L.: Analysis of ice plains of the Filchner-Ronne Ice Shelf, Antarctica, using ICESat laser altimetry, J. Glaciol., 57, 965-975, 2011.

Church, J. A., Clark, P. U., Cazenave, A., Gregory, J. M., Jevrejeva, S., Levermann, A., Merrifield, M. A., Milne, G. A., Nerem, R. S., Nunn, P. D., Payne, A. J., Pfeffer, W. T., Stammer, D., and Unnikrishnan, A. S.: Sea Level Change, in: Climate Change 2013: The Physical Science Basis. Contribution of Working Group I to the Fifth Assessment Report of the Intergovernmental Panel on Climate Change, edited by: Stocker, T. F., Qin, D., Plattner, G.K., Tignor, M., Allen, S. K., Boschung, J., Nauels, A., Xia, Y., Bex, V., and Midgley, P. M., Cambridge University Press, Cambridge, UK and New York, NY, USA, 1170-1175, 2013.

Cuffey, K. M. and Patterson, W. S. B.: The Physics of Glaciers, Fourth Edn., Butterworth-Heineman, 30 Corporate Drive, Suite 400, Burlington, MA 01803, USA, 2010.

Doake, C. S. M., Frolich, R. M., Mantripp, D. R., Smith, A. M., and Vaughan, D. G.: Glaciological studies on Rutford ice stream, Antarctica, J. Geophys. Res., 92, 8951-8960, 1987.

Doake, C. S. M., Corr, H. F. J., Nicholls, K. W., Gaffikin, A., Jenkins, A., Bertiger, W. I., and King, M. A.: Tide-induced lateral movement of Brunt Ice Shelf, Antarctica, Geophys. Res. Lett., 29, 1226, doi:10.1029/2001GL014606, 2002.

Engelhardt, H. and Kamb, B.: Basal sliding of ice stream B, West Antarctica, J. Glaciol., 44, 223-230, 1998.

Fricker, H. A. and Padman, L.: Tides on Filchner-Ronne Ice Shelf from ERS radar altimetry, Geophys. Res. Lett., 29, 1622, doi:10.1029/2001GL014175, 2002.

Goldberg, D. N., Schoof, C., and Sergienko, O. V.: Stick-slip motion of an Antarctic Ice Stream: The effects of viscoelasticity, J. Geophys. Res.-Sol. Ea., 119, 1564-1580, 2014.

Gudmundsson, G. H.: Transmission of basal variability to a glacier surface, J. Geophys. Res.-Sol. Ea., 108, 2253, doi:10.1029/2002JB002107 2003.

Gudmundsson, G. H.: Fortnightly variations in the flow velocity of Rutford Ice Stream, West Antarctica., Nature, 444, 1063-1064, 2006.

Gudmundsson, G. H.: Tides and the flow of Rutford Ice Stream, West Antarctica, J. Geophys. Res., 112, F04007, doi:10.1029/2006JF000731, 2007.

Gudmundsson, G. H.: Ice-stream response to ocean tides and the form of the basal sliding law, The Cryosphere, 5, 259-270, doi:10.5194/tc-5-259-2011, 2011.

Harrison, W. D.: Short-period observations of speed, strain and seismicity on Ice Stream B, Antarctica, J. Glaciol., 39, 463-470, 1993.
Heinert, M. and Riedel, B.: Parametric modelling of the geometrical ice-ocean interaction in the Ekstroemisen grounding zone based on short time-series, Geophys. J. Int., 169, 407-420, 2007.

Holdsworth, G.: Flexure of a floating ice tongue, J. Glaciol., 8, 385397, 1969.

Holdsworth, G.: Tidal interaction with ice shelves, Ann. Geophys., 33, 133-146, 1977,

http://www.ann-geophys.net/33/133/1977/.

King, M. A. and Aoki, S.: Tidal observations on floating ice using a single GPS receiver, Geophys. Res. Lett., 30, 1138, doi:10.1029/2002GL016182, 2003.

King, M. A., Penna, N. T., Clarke, P. J., and King, E. C.: Validation of ocean tide models around Antarctica using onshore GPS and gravity data, J. Geophys. Res., 110, B08401, doi:10.1029/2004JB003390, 2005.

King, M. A., Murray, T., and Smith, A. M.: Non-linear responses of Rutford Ice Stream, Antarctica, to semi-diurnal and diurnal tidal forcing, J. Glaciol., 56, 167-176, 2010.

King, M. A., Makinson, K., and Gudmundsson, G. H.: Nonlinear interaction between ocean tides and the Larsen C Ice Shelf system, Geophys. Res. Lett., 38, L08501, doi:10.1029/2011GL046680, 2011.

Makinson, K., Holland, P. R., Jenkins, A., Nicholls, K. W., and Holland, D. M.: Influence of tides on melting and freezing beneath Filchner-Ronne Ice Shelf, Antarctica, Geophys. Res. Lett., 38, L06601, doi:10.1029/2010GL046462, 2011.

Makinson, K., King, M. A., Nicholls, K. W., and Gudmundsson, G. H.: Diurnal and semidiurnal tide-induced lateral movement of Ronne Ice Shelf, Antarctica, Geophys. Res. Lett., 39, L10501, doi:10.1029/2012GL051636, 2012.

MARC: Marc users manual, MSC Software Corporation, 2 MacArthur Place, Santa Ana, CA 92707, USA, 2013.

Marsh, O. J., Rack, W., Floricioiu, D., Golledge, N. R., and Lawson, W.: Tidally induced velocity variations of the Beardmore Glacier, Antarctica, and their representation in satellite measurements of ice velocity, The Cryosphere, 7, 1375-1384, doi:10.5194/tc-71375-2013, 2013.

Murray, T., Smith, A. M., King, M. A., and Weedon, G. P.: Ice flow modulated by tides at up to annual periods at Rutford Ice Stream, West Antarctica, Geophys. Res. Lett., 34, 6-11, 2007.

Padman, L., Erofeeva, S., and Joughin, I.: Tides of the Ross Sea and Ross Ice Shelf cavity, Antarct. Sci., 15, 31-40, 2002a.

Padman, L., Fricker, H. A., Coleman, R., Howard, S., and Erofeeva, S. Y.: A new tide model for the Antarctic ice shelves and seas, Ann. Glaciol., 34, 247-254, 2002b.

Padman, L., Erofeeva, S. Y., and Fricker, H. A.: Improving Antarctic tide models by assimilation of ICESat laser altimetry over ice shelves, Geophys. Res. Lett., 35, L22504, doi:10.1029/2008GL035592, 2008.

Pawlowicz, R., Beardsley, B., and Lentz, S.: Classical tidal harmonic analysis including error estimates in MATLAB using T_TIDE, Comput. Geol., 28, 929-937, 2002.

Reeh, N., Christensen, E. L., Mayer, C., and Olesen, O. B.: Tidal bending of glaciers: a linear viscoelastic approach, Ann. Glaciol., 37, 83-89, 2003.

Robertston, R. A., Padman, L., and Egbert, G. D.: Tides in the Weddel Sea in Ocean, Ice and Atmosphere, Interactions at the Antarctic Continental Margin, Ant. Res. Ser., AGU, Washington D.C., 341-369, 1998. 
Sayag, R. and Worster, M. G.: Elastic dynamics and tidal migration of grounding lines modify subglacial lubrication and melting, Geophys. Res. Lett., 40, 5877-5881, doi:10.1002/2013GL057942, 2013.

Sergienko, O. V., Macayeal, D. R., and Bindschadler, R.: Stick-slip behavior of ice streams: modeling investigations, Ann. Glaciol., 50, 87-94, 2009.

Smith, A. M.: The use of tiltmeters to study the dynamics of Antarctic ice-shelf grounding lines, J. Glaciol., 37, 51-58, 1991.

Thompson, J., Simons, M., and Tsai, V. C.: Modeling the elastic transmission of tidal stresses to great distances inland in channelized ice streams, The Cryosphere Discuss., 8, 2119-2177, doi:10.5194/tcd-8-2119-2014, 2014.

Tsai, V. C. and Gudmundsson, G. H.: An improved model for tidally-modulated grounding line migration, J. Glaciol., in review, 2014.

Vaughan, D. G.: How does the Antarctic ice sheet affect sea level rise?, Science, 308, 1877-1878, 2005.
Walker, R. T., Christianson, K., Parizek, B. R., Anandakrishnan, S., and Alley, R. B.: A viscoelastic flowline model applied to tidal forcing of Bindschadler Ice Stream, West Antarctica, Earth Planet. Sc. Lett., 319-320, 128-132, 2012.

Walters, R. A.: Small-amplitude, short-period variations in the speed of a tide-water glacier in south-central alaska, U. S. A., Ann. Glaciol., 12, 187-191, 1989.

Weertman, J.: On the sliding of glaciers, J. Glaciol., 3, 33-38, 1957.

Wiens, D. A., Anandakrishnan, S., Winberry, J. P., and King, M. A.: Simultaneous teleseismic and geodetic observations of the stick-slip motion of an Antarctic ice stream, Nature, 453, 770-774, 2008.

Williams, R. T. and Robinson, E. S.: The Ocean Tide in the Southern Ross Sea, J. Geophys. Res., 85, 6689-6696, 1980.

Winberry, J. P., Anandakrishnan, S., Alley, R. B., Bindschadler, R., and King, M. A.: Basal mechanics of ice streams: Insights from the stick-slip motion of Whillans Ice Stream, West Antarctica, J. Geophys. Res., 114, F01016, doi:10.1029/2008JF001035, 2009. 